\title{
Video Capsule Endoscopy and Device-Assisted Enteroscopy
}

\author{
Mark Hanscom $^{1} \cdot$ Courtney Stead $^{2} \cdot$ Harris Feldman ${ }^{2} \cdot$ Neil B. Marya $^{1} \cdot$ David Cave $^{1}$
}

Accepted: 20 April 2021 / Published online: 12 August 2021

(c) The Author(s), under exclusive licence to Springer Science+Business

Media, LLC, part of Springer Nature 2021

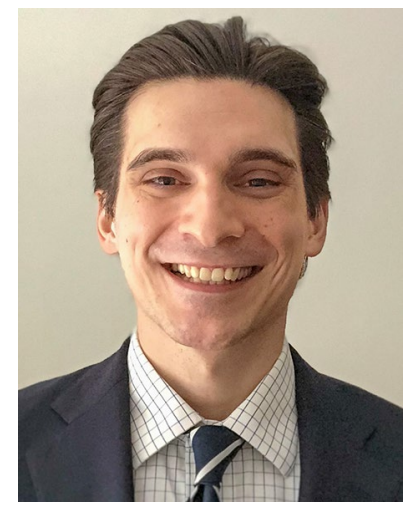

Mark Hanscom

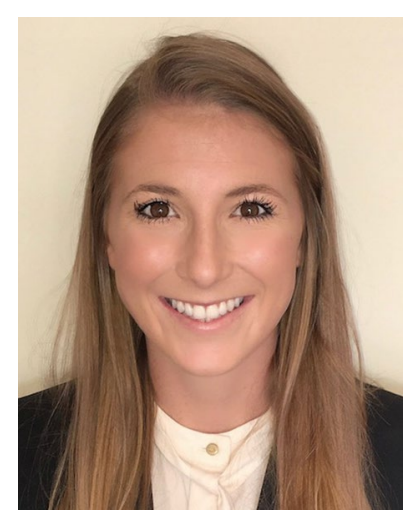

Courtney Stead

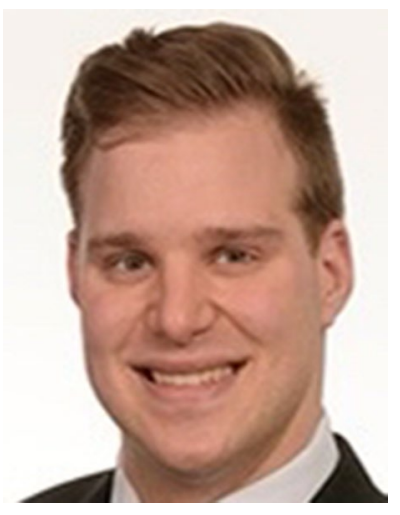

Harris Feldman

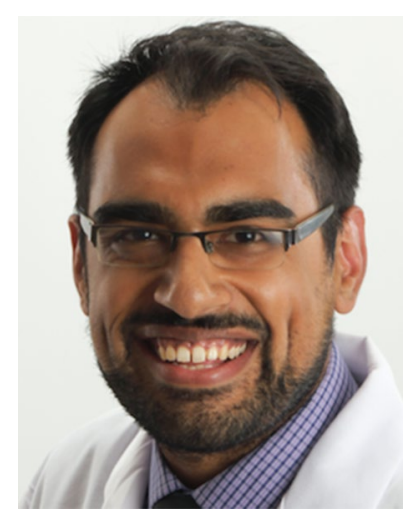

Neil B. Marya

Extended author information available on the last page of the article 


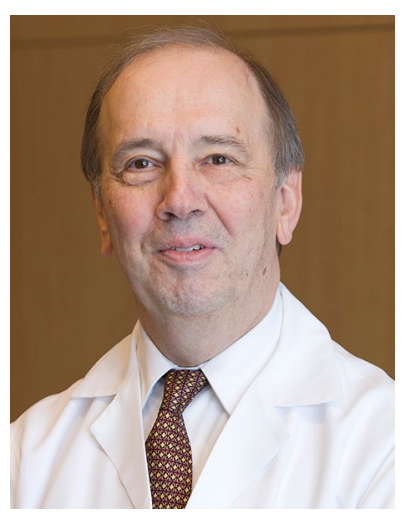

David Cave

\section{Video Capsule Endoscopy}

\section{Introduction}

The paradigm of video capsule endoscopy (VCE) is changing. Once dismissed as a pipedream, VCE has overcome technological constraints and perceptions of limited demand and established itself as an important tool in the practicing gastroenterologist's panoply. Introduced to the public in 2001, VCE has proliferated over the past two decades to become a standard diagnostic test for a multitude of diseases, including small bowel bleeding (SBB), Crohn's disease (CD), and small intestinal neoplasia. Newer platforms are no longer limited to the small intestine alone, with recent developments introducing esophageal capsule endoscopy (ECE) and colon capsule endoscopy (CCE). In the near future, VCE is also poised to revolutionize the approach to gastrointestinal bleeding (GIB) in the acute care setting. Indeed, capsule endoscopic technologies have come far since their debut in 2001 and, with more hardware and software advancements on the horizon, show no sign of abating.

\section{Technologies}

There are now multiple VCE platforms available — most with multiple generations. The most common VCE platforms in use in the USA are the PillCam (Medtronic and Given Imaging Ltd., Yoqneam, Israel) and the EndoCapsule (Olympus Medical Systems Corp., Tokyo, Japan). Other platforms are listed in Table 1.

Different capsule models differ in terms of technological specifications (Table 1). In general, images are captured within the capsule and transmitted to an external sensor, which is often incorporated into a sensor belt or vest. Once the capsule's run-time is over, the belt can be removed, and the data recorder attached to a remote docking station for data download and review. Newer generations of VCE also incorporate a real-time viewer (RTV) into the data recorder that allows one to obtain an immediate, ad hoc visual of the capsule's imaging feed [1]. One notable exception involves the CapsoCam, which retains acquired data and must be recovered by the patient. The capsule can then be mailed to a central reading facility, which in turn sends the results back to the ordering physician. This works well for physicians who do not use video capsules often, or who do not want to set up their own facilities.

Small studies have compared the various capsule models against one another, with no single capsule model demonstrating substantial advantages over its competitors. In one comparison between the EndoCapsule and PillCam among 51 patients, the inter-capsule agreement was $74.5 \%$ [2]. In a separate trial among 45 patients, there was a non-significant trend toward increased detection of bleeding lesions with the EndoCapsule compared to the PillCam SB, although this was attributed to, in part, the longer recording times of the EndoCapsule [3]. Comparisons between other capsule models have demonstrated similar results, with inter-capsule agreement reaching up to $87.5 \%$ [4-8]. Thus, the decision of which capsule to use should be based on available resources.

\section{Procedure and Preparation}

Preparation prior to VCE should include medication adjustment, a period of fasting, and an optional bowel cleansing. Oral iron supplementation, in particular, should be discontinued 3 days prior to procedure as it can mimic melena and darken the images. The standard pre-procedure fast is around 10-12 h or overnight. The decision of whether or not to require a bowel cleansing is controversial. There is some evidence that purgative bowl preparation increases both small bowel cleansing and diagnostic yield compared to a clear liquid diet (CLD) preparation [9, 10]. However, in a recent large randomized control trial (RCT), Hookey and colleagues compared two purgative bowel preparations against a CLD regimen among 175 patients undergoing VCE. There was no difference in small bowel cleansing or diagnostic yield in the patients who used polyethylene glycol (PEG) or sodium picosulfate plus magnesium sulfate compared to those who used a CLD alone [11]. Furthermore, patients overwhelmingly preferred the CLD preparation. More recent studies have also supported an equivalent diagnostic yield with and without bowel cleansing [12]. Considering the cumulative evidence, it is our current practice not to perform a bowel cleansing outside of an overnight fast.

Following capsule ingestion, patients can start non-carbonated liquids after $2 \mathrm{~h}$, and solids and medications after $4 \mathrm{~h}$. The biggest obstacle to successful examination is poor image quality. Capsules can be administered with water and 
Table 1 Technical specifications of various video capsule platforms

\begin{tabular}{|c|c|c|c|c|c|c|c|c|}
\hline & Manufacturer & Length (mm) & Diameter (mm) & Weight $(\mathrm{g})$ & Cameras (n) & FPS & $\begin{array}{l}\text { Viewing } \\
\text { angle (deg) }\end{array}$ & Battery life (h) \\
\hline PillCam SB3 & Medtronic & 26.2 & 11.4 & 3 & 1 & $2-6$ & 156 & $8+$ or $12+$ \\
\hline PillCam Crohn's Capsule & Medtronic & 32.3 & 11.6 & 2.9 & 2 & $4-35$ & 168 & $10+$ \\
\hline PillCam UGI & Medtronic & 32.3 & 11.6 & 2.9 & 2 & $18-35$ & 172 & 1.5 \\
\hline PillCam COLON 2 & Medtronic & 32.3 & 11.6 & 2.9 & 2 & $4-35$ & 172 & $10+$ \\
\hline EndoCapsule & Olympus & 26 & 11 & 3.5 & 1 & 2 & 145 & $12+$ \\
\hline MiroCam & Intromedic & 24.5 & 10.8 & 3.25 & 1 & 3 & 170 & $11+$ \\
\hline OMOM & Jinshan & 27.9 & 13 & 6 & 1 & 2 & 140 & $6-8+$ \\
\hline
\end{tabular}

simethicone in order to reduce intraluminal bubbles and improve small bowel visualization, although this has not definitively translated to improved diagnostic yields $[13,14]$. Prolonged transit time through the stomach can also lead to incomplete examinations of the small bowel. In patients with gastroparesis, efforts should be made to facilitate gastric passage. Techniques to do so include moving the patient into the right lateral position, asking the patient to ambulate, and using purgative or prokinetic agents. If a RTV is available, gastric transit time can be monitored after $30 \mathrm{~min}$ to confirm passage into the small intestine. If the capsule remains in the stomach, administration of metoclopramide, erythromycin, domperidone, or the previously mentioned non-pharmacologic techniques can be attempted to facilitate passage. The use of a small amount of PEG after administration can also improve small intestine visualization [15]. Small studies have shown that the use of a RTV in combination with on-demand preparations can reduce gastric passage time and increase the rate of complete small bowel evaluation [16, 17].

Data collection and review can be cumbersome. On average, it takes 15-40 min to review each study. The quad-view can be helpful, as it places four images on the screen at once, slowing the rate of change of each image, but increasing overall reading speed by up to $50 \%$. Efforts should be made to establish a standard pattern of reading. In our current practice, we first locate the cecum to confirm completion. Then, the remaining critical landmarks (first gastric image, first duodenal image) are identified. The suspected blood indicator (SBI) is activated and scanned for potential sources of bleeding and concerning images are reviewed. The images are then reviewed in full chronological order (Table 2).

Complications from VCE are rare (Table 3). The most common complications are capsule aspiration and capsule retention, with the latter defined as capsule retention in the gastrointestinal tract for greater than 2 weeks. VCE aspiration occurs in 1 in 1000 cases and is more often seen in older patients with comorbid swallowing disorders [18]. If the capsule is not expectorated, it can be retrieved using rigid bronchoscopy [19-23]. The risk of capsule retention increases depending on the indication for VCE (Table 3). The incidence of capsule retention can be lessened with the use of a patency capsule, which consists of a radiofrequency identification (RFID) tag, secured within a lactose-barium mixture, covered with a parylene $\mathrm{C}$ coating, and capped with biodegradable plugs at both ends. Should the capsule become retained, gastrointestinal fluids can infiltrate the biodegradable plugs and dissolve the lactose-barium mixture, allowing passage through a stricture. A radiograph at $30 \mathrm{~h}$ after ingestion can detect a retained capsule before it degrades. Indications for patency capsule include established $\mathrm{CD}$, prior abdominopelvic radiation or small bowel resection, prolonged non-steroidal anti-inflammatory drug (NSAID) use, or suspicion for small intestinal stenosis. If retention occurs, the capsule should be retrieved either endoscopically or surgically. However, retention for years, without harm, has been anecdotally reported [24-26].

\section{Small Bowel Bleeding}

In current clinical practice, the most common use for VCE is in the evaluation of obscure gastrointestinal bleeding (OGIB). Current clinical guidelines recommend VCE for small bowel evaluation after upper endoscopy and colonoscopy have failed to identify a source of bleeding. In such cases, 5-10\% of patients will ultimately be diagnosed with SBB [27].

The diagnostic yield for VCE in patients with OGIB is $38-83 \%$, with higher rates reported in overt bleeding than in occult bleeding (Table 4) [28]. Factors that influence diagnostic yield include sex, age, hemoglobin level, duration of bleeding, time from bleeding to capsule deployment, and inpatient status [29-31]. Marya and colleagues developed a scoring system to predict a positive diagnosis on VCE for suspected SBB in order to aid clinicians in determining which patients would benefit from VCE. In their analysis, three variables - inpatient status with overt bleeding, hemoglobin $<6.4 \mathrm{~g} / \mathrm{dL}$, and age $<54$-years-old-were independent predictors of a diagnosis on VCE. The scoring system had a sensitivity and specificity of $91.6 \%$ and $30.6 \%$, 
Table 2 Steps in capsule administration and reading

\begin{tabular}{|c|c|}
\hline Capsule preparation and administration & Capsule reading \\
\hline [Optional] Administer patency capsule & $\begin{array}{l}\text { Look at the last image first and track backwards until the first cecal } \\
\text { image is identified. Mark it }\end{array}$ \\
\hline Starting $72 \mathrm{~h}$ prior, avoid iron supplements & Locate and mark the first duodenal image \\
\hline [Optional] Perform a purgative bowel preparation & Locate and mark the first gastric image \\
\hline Starting $10-12 \mathrm{~h}$ prior, perform an overnight fast & Scan the SBI for signs of bleeding \\
\hline $\begin{array}{l}\text { Morning of procedure, counsel on risks and benefits, obtain informed } \\
\text { consent }\end{array}$ & $\begin{array}{l}\text { [Optional] Perform a first pass using the quick time viewer if urgent } \\
\text { read needed }\end{array}$ \\
\hline Ingest capsule with water [optional and simethicone] & $\begin{array}{l}\text { Look at the first image and perform a full chronological read, marking } \\
\text { areas of concern }\end{array}$ \\
\hline \multicolumn{2}{|l|}{ Allow capsule to complete full run-time of $\sim 8-12+$ hours } \\
\hline \multicolumn{2}{|l|}{$\begin{array}{l}\text { Morning following procedure, patient returns capsule equipment and } \\
\text { recorder }\end{array}$} \\
\hline Download capsule images for reading & \\
\hline
\end{tabular}

Table 3 Complications of VCE and the associated management

\begin{tabular}{lll}
\hline Complication & $\begin{array}{l}\text { Risk of complication } \\
(\%)\end{array}$ & Management \\
\hline Aspiration & 0.1 & $\begin{array}{c}\text { If not spontaneously expectorated, can } \\
\text { retrieve with rigid bronchoscopy } \\
\text { Retrieve endoscopically, or surgically* }\end{array}$ \\
$\begin{array}{l}\text { Retention } \\
\text { OGIB }\end{array}$ & $1-2$ & \\
Suspected Crohn's disease & $1-2$ & \\
Established Crohn's disease & $9-13$ & \\
Small bowel tumors & $5-15$ & \\
\hline
\end{tabular}

*While retrieval is recommended because of the rare risk of perforation, most cases of retention are asymptomatic and anecdotal reports have demonstrated retention for years without harm respectively, and could prove helpful in identifying patients in whom VCE is likely to be of low yield [32].

Overall, VCE has an excellent positive (PPV) and negative predictive value (NPV) of up to $94-97 \%$ and $83-100 \%$, respectively [33-35]. In patients with a negative VCE, the rates of rebleeding are also significantly lowered to between 6 and 27\% [16, 36, 37]. Repeat VCE has an incremental yield of $35-75 \%$ and should be considered in patients with a change in clinical condition or a new hemoglobin decrease $[38,39]$. VCE is superior to most other diagnostic modalities in the detection of small intestinal bleeding. In multiple studies, VCE has demonstrated superior sensitivity compared to computed tomography (CT) angiography ( $72 \%$ vs. $24 \%$ ), mesenteric angiography ( $72 \%$ vs. $56 \%$ ), barium radiography (67\% vs. $8 \%$ ), and push enteroscopy (63\% vs. $28 \%$ ) [40, 41].

One of the most important factors contributing to the diagnostic yield of VCE is its timing in relation to the onset of gastrointestinal bleeding. Current guidelines recommend VCE as soon as possible after the onset of bleeding and optimally within 14 days [42]. Immediate VCE can detect a source of bleeding in up to $87 \%$ of cases [43]. However, the rate of detection decreases down to $35 \%$ as more time passes from presentation [44]. In one trial, VCE within $72 \mathrm{~h}$, compared to after $72 \mathrm{~h}$, led to an incremental yield of $16 \%$ and resulted in significantly more therapeutic procedures being performed (18.9\% vs. $7.4 \%)$ [45].

\section{Crohn's Disease}

Outside of OGIB, the evaluation of suspected CD is next most common use of VCE. Ileo-colonoscopy remains the test of choice for diagnosing CD. However, up to $30 \%$ of patients with $\mathrm{CD}$ will have isolated small bowel disease, which can be difficult to diagnose with ileo-colonoscopy alone [46]. In patients with characteristic gastrointestinal complaints and other manifestations of $\mathrm{CD}$, current guidelines have suggested VCE as a useful adjunct in the diagnosis of small bowel CD [46].

VCE is superior to most other modalities in detecting small intestinal CD. Yields of VCE in suspected CD have been demonstrated to be superior to small bowel radiography (52\% vs. $16 \%$ ), CT enterography (CTE) (68\% vs. $21 \%$ ), and 
ileo-colonoscopy (47\% vs. 25\%) [47]. Similarly, yields of VCE in established CD have been demonstrated to be superior to push enteroscopy (66\% vs. $9 \%$ ), small bowel radiography ( $71 \%$ vs. $36 \%$ ), and CTE (71\% vs. 39\%) (Table 4) [47]. In one prospective trial of 93 patients, Jensen and colleagues compared VCE to CTE and magnetic resonance enterography (MRE). The sensitivity and specificity of VCE for CD of the terminal ileum were $100 \%$ and $91 \%$, respectively, being superior to both CTE $(76 \%, 85 \%)$ and MRE $(81 \%, 86 \%)$ [48]. In addition, VCE has an excellent NPV in suspected $\mathrm{CD}$ of $96 \%$ [49]. The number needed to test (NNT) to yield an additional diagnosis of CD with VCE compared to push enteroscopy or small bowel radiography is 3 , and compared to ileo-colonoscopy is 7 [41].

In established CD, VCE can also be useful in the detection of active disease, postoperative recurrence, and mucosal healing, which is the currently accepted yardstick for remission. In several small retrospective studies, VCE has been shown to change clinical management in patients with $C D$ who present with gastrointestinal complaints, either by leading providers to escalate treatment or to seek alternative diagnoses [50-52]. In one large retrospective review of 128 patients with CD who underwent VCE, abnormal findings were detected in $77.9 \%$ of patients. In the 3 months following VCE, $61.6 \%$ of these patients underwent a change in treatment, with severe findings on VCE associated with significantly greater medication changes $(73.2 \%$ vs. $51.1 \%)$, addition of medications ( $58.5 \%$ vs. $22.2 \%$ ), and surgeries (21.9\% vs. $4.4 \%$ ) [53]. In postoperative patients with an ileocolonic anastomosis, VCE is both better tolerated and better able to detect proximal recurrence of disease [54]. In patients undergoing treatment for $\mathrm{CD}$, small studies have demonstrated that VCE can also detect mucosal healing [55].

Several scoring systems have been proposed to grade small bowel inflammation in CD, including the Lewis Index, Capsule Endoscopy Structured Terminology, and Capsule Endoscopy Crohn's Disease Activity Index. For now, these systems remain mostly research tools, limited by poor specificity for diagnosing $\mathrm{CD}$ and poor correlation with clinical symptoms and the Crohn's Disease Activity Index score [56-58].

\section{Special Circumstances}

Multiple other conditions have been studied using VCE (Table 4). Two situations deserve special mention: acute gastrointestinal bleeding in the emergency department (ED) and suspected gastrointestinal bleeding in resource-limited settings.

The evaluation of acute gastrointestinal bleeding in the ED has historically been the domain of conventional endoscopy. However, accumulating evidence suggests that a VCE-first protocol can increase bleeding detection, reduce admissions, and lower costs. For example, in one RCT from Marya and colleagues, the use of a VCE-first approach in patients with GIB in the ED improved the detection of active or recent bleeding compared to the standard of care $(64.3 \%$ vs. 31.1\%) [59]. Most of this difference came from the identification of vascular and colonic lesions, highlighting the potential of VCE as a tool to guide subsequent therapeutic procedures. The identification of a bleeding colonic lesion on VCE, for instance, could spare patients from an unneeded upper endoscopy and allow them to proceed straight to colonoscopy, reducing both the number of invasive procedures and the duration of admission. Sung and colleagues likewise demonstrated a reduction in admission rates from the ED with a VCE-first approach from 100 to 19\% [60]. VCE has also demonstrated effectiveness as a risk stratification tool in the ED, being more sensitive than nasogastric tube aspiration $(83.3 \%$ vs. $33.3 \%)$ and more accurate than the GlasgowBlatchford and Rockall scores [56, 61]. In a decision analysis comparison, Meltzer and colleagues found that a VCE-first approach to GIB in the ED was the preferred approach in terms of both cost and quality associated life years (QALYs) compared to stratification with the Blatchford score, NGT aspiration, or an all-admit approach [62].
Table 4 Testing characteristic of VCE in various studied conditions

\begin{tabular}{llcrrr}
\hline Indication & $\begin{array}{l}\text { Diagnostic } \\
\text { yield }(\%)\end{array}$ & Sensitivity (\%) & Specificity (\%) & PPV & NPV \\
\hline Obscure gastrointestinal bleeding & & $38-83$ & 84 & $94-97$ & $83-100$ \\
Crohn's disease & & 100 & 91 & 76 & 100 \\
Celiac disease & & $70-95$ & $63-100$ & $96-100$ & $71-89$ \\
Acute gastrointestinal bleeding & $64-87$ & & & & \\
Abdominal pain & $6-21$ & & & & \\
NSAID enteropathy & $5-60$ & & & & \\
Familial adenomatous polyps & 29 & & & & \\
Peutz-Jeghers Syndrome & $22-59$ & & & & \\
\hline
\end{tabular}

In conditions where there are not enough data to report sensitivity and specificity, diagnostic yield is reported instead 
In resource-limited settings, VCE can also help reduce unneeded procedures. For example, during the SARS-CoV-2 pandemic, Hakimian and colleagues compared a VCE-first approach to standard of care in patients presenting with GIB. Compared to standard of care, patients who underwent VCE as the first-line test required fewer invasive procedures ( $44 \%$ vs. $96 \%$ ) with no significant changes in mortality, rebleeding, or readmissions for rebleeding [63]. VCE thus reduced unneeded exposure to aerosol-generating procedures and utilized far fewer resources including personnel, procedure space, and personal protective equipment (PPE). It is not difficult to imagine how similar strategies could help in other resource constrained settings.

\section{Esophageal Capsule Endoscopy}

The esophageal video capsule (PillCam ESO, Given Imaging Ltd., Yoqneam, Israel-now discontinued and replaced with PillCam Upper GI) received FDA approval for clinical use in 2004. Preparation is easier than with the PillCam SB as patients need to fast for just $1 \mathrm{~h}$ prior to administration. The capsule is administered in the left lateral decubitus position and its position monitored using the RTV on the recorder.

Current indications for ECE include screening for esophagitis (Table 5). Compared to upper endoscopy, the sensitivity, specificity, PPV, and NPV of the ECE for erosive esophagitis is $89 \%, 99 \%, 97 \%$, and $94 \%$, respectively $[64,65]$. However, ECE was preferred over conventional endoscopy by patients in all cases [65]. Other conditions in which ECE has been studied include Barrett's esophagus and esophageal varices (Table 5) [65-67].

\section{Colon Capsule Endoscopy}

The use of the colon video capsule (PillCam COLON2, Medtronic and Given Imaging Ltd., Yoqneam, Israel) for colorectal cancer screening was first demonstrated in 2006 [64]. Compared to the small bowel capsule, the colon capsule is larger, with more cameras, and a larger viewing angle.

Colon capsule endoscopy (CCE) is a safe procedure without major complications [68]. Limitations include the need for a substantial bowel preparation, including a "booster" dose of laxatives during the procedure. Other obstacles impeding acceptance include the lack of a specific CPT code, reluctance from insurance companies to reimburse for CCE, and the technical challenge of reading two video streams at once.

Despite these challenges, CCE has demonstrated clinical effectiveness (Table 6). In colorectal cancer screening, CCE has been shown to have a sensitivity and specificity of $89 \%$ and $84 \%$, respectively, in the detection of colorectal polyps $>6 \mathrm{~mm}$ [69]. Significant findings, including polyps $>6 \mathrm{~mm}$ in size or $>3$ polyps regardless of size, should prompt conventional colonoscopy for removal. If, on the other hand, no significant lesions are found, then $\mathrm{CCE}$ or an equivalent screening test should be repeated in 5 years for surveillance [68].

Other situations in which CCE might be of benefit include incomplete colonoscopy, patient preference against colonoscopy, and contraindication to colonoscopy. If performed for incomplete colonoscopy, CCE can be performed on the same day as the bowel preparation will have already been administered. Identification of a landmark already seen on incomplete colonoscopy, or excretion of the capsule, then documents a complete procedure. Several prospective studies have evaluated the use of CCE following incomplete colonoscopy with promising results. The technical success rate for completion of colonoscopy ranges from 85 to $98 \%$, with additional findings reported in $14-45 \%$ of cases [70-72]. CCE also outperforms CT colonography (CTC) in this setting. In one trial of 98 patients, for example, CCE detected polyps $>6 \mathrm{~mm}$ in $24.5 \%$ of patients, whereas CTC detected polyps in just $12.2 \%$ of patients [73].

\section{Future Developments}

In the near future, hardware and software advancements will once again transform capsule endoscopy. Hardware advancements thus far have focused on improved imaging, improved locomotion, and improved therapeutics. In addition to technological upgrades (increased battery power, wider angles of view, automatic control of light exposure), new modes of imaging are being developed. These modes of imaging include flexible spectral imaging enhancement (FICE) and narrow-band imaging (NBI), each designed to highlight specific mucosal abnormalities, as well as microultrasound and thermometric imaging, designed to visualize submucosal lesions. Parallel to imaging advancements, locomotive advancements are also progressing. External locomotion using magnets, also called magnet-controlled endoscopy (MCE), has been demonstrated to be effective in clinical studies, with the capsule endoscope being able to be manipulated into position and visualize target mucosa in $82-100 \%$ of cases [74-76]. In one large, multicenter trial of 350 patients with abdominal pain, MCE demonstrated a sensitivity, specificity, PPV, and NPV of $90.4 \%, 94.7 \%$, $87.9 \%$, and $95.9 \%$ when compared to conventional upper endoscopy. No significant lesions were missed and just 5 patients (1.4\%) reported adverse events [77]. Therapeutic capsule endoscopy remains a relatively esoteric but promising technology. Multiple new generations of capsules have experimented with the ability to biopsy tissue or otherwise diagnose diseases through novel optical and biochemical means [78-82]. 
Table 5 Testing characteristics of ECE in studied conditions

\begin{tabular}{lllrl}
\hline Indication & Sensitivity (\%) & Specificity (\%) & PPV & NPV \\
\hline Esophagitis & 90 & 100 & 100 & 95 \\
Barrett's esophagus & $78-97$ & $90-100$ & 100 & 98 \\
Esophageal varices & $84-86$ & $81-88$ & 92 & 77 \\
\hline
\end{tabular}

Software advancements promise to redefine the use of VCE in the coming decade. Perhaps the most meaningful advancement will be the incorporation of artificial intelligence (AI). Saito and colleagues have recently developed a convolutional neural network (CNN) that was able to detect protruding lesions with a sensitivity and specificity of $90.7 \%$ and $79.8 \%$ [83]. The same network was able to detect blood in the gastrointestinal tract with an accuracy of $99.89 \%$, and erosions and deep ulcerations with an accuracy of $90.8 \%$ $[84,85]$. The use of a CNN has been demonstrated to reduce the reading time of VCE from an average of $96.6 \mathrm{~min}$ to 5.9 min, eliminating one of the most common challenges to adoption [86].

\section{Device-Assisted Enteroscopy}

\section{Introduction}

For a long time, the small bowel remained an effective "noman's land" outside of therapeutic reach. Patients with gastrointestinal bleeding could undergo an upper endoscopy and colonoscopy, and those without an identified lesion were then diagnosed with OGIB reflecting the limitations of endoscopic investigations. Severe conditions could be better evaluated with surgical-assisted enteroscopy, but for the most part, lesions were left unidentified. Since then, technological advancements have turned small bowel exploration from a promise into reality, and small bowel investigation is now a core part of the practicing gastroenterologist's toolkit. The introduction of double-balloon enteroscopy (DBE) has led to a series of advancements in device-assisted enteroscopy (DAE), including single-balloon enteroscopy (SBE) and spiral enteroscopy (SE) [87].

\section{Double-Balloon Enteroscopy}

Introduced in 2001 and still used in clinical practice now, DBE (Fujifilm Medical Systems Inc., USA) was one of the first methods made to investigate the small bowel. In DBE, a push-and-pull method is used to advance the enteroscope through the small bowel. The DBE system comprises an enteroscope, an overtube, and balloon-pump system. Latex balloons are attached to the distal ends of both the enteroscope and overtube, and with alternating inflation and deflation of each balloon, the enteroscope can be advanced.

There are multiple models of DBE available in clinical practice. The diagnostic model (EN-580 T) comprises an external diameter of $8.5 \mathrm{~mm}$ and an accessory channel of $2.2 \mathrm{~mm}$, compared to the therapeutic model (EN-580XP), which comprises an external diameter of $9.5 \mathrm{~mm}$ and an accessory channel of $2.8 \mathrm{~mm}$. Each channel allows for the passage of needed tools including biopsy forceps, injection needles, thermal probes, and hemostatic clips. There is also a short-model (EI-580BT) available, which is designed for patients with challenging anatomy, such as post-surgical Roux-en-Y reconstruction [88, 89].

The main benefit of DBE is the extent of small bowel it can reach, surpassing that of push enteroscopy and ileoscopy. DBE can be performed from either the oral or rectal route, although depth of advancement is often greater with the former. DBE can reach up to $240-360 \mathrm{~cm}$ past the ligament of Treitz with the oral approach, and up to $102-140 \mathrm{~cm}$ past the ileocecal valve with the rectal approach [90]. The most common indication for $\mathrm{DBE}$ is the diagnosis and treatment of OGIB, accounting for $36-100 \%$ of cases. Other common indications for DBE include tissue acquisition from the small bowel and evaluation of abnormal imaging findings out of range of a conventional endoscope [89, 91]. More rare indications for DBE include small bowel obstruction $(8.9 \%)$, suspected tumors $(8.3 \%)$, inflammatory bowel disease, postoperative evaluation, and foreign body removal [92].

There is a learning curve to successful DBE, with more experienced providers demonstrating higher success rates and lower procedural times. Overall, the diagnostic yield has been estimated in the range of $65-68 \%$ and is highest when
Table 6 Testing characteristics of CCE in studied conditions

\begin{tabular}{llllll}
\hline Indication & Sensitivity (\%) & Specificity (\%) & $\begin{array}{l}\text { Diagnostic } \\
\text { yield (\%) }\end{array}$ & PPV & NPV \\
\hline $\begin{array}{l}\text { Screening for colorectal } \\
\text { polyps } \geq 6 \text { mm }\end{array}$ & $89-98$ & $76-84$ & & 93 & 92 \\
$\begin{array}{l}\text { Ulcerative colitis } \\
\begin{array}{l}\text { Incomplete colonoscopy } \\
\hline\end{array}\end{array}$ & 89 & 75 & 24.5 & 93 & $65-96^{*}$ \\
\hline
\end{tabular}

*The PPV after incomplete colonoscopy increases from $85 \%$ in polyps $\geq 10 \mathrm{~mm}$ to $96 \%$ in polyps $\geq 6 \mathrm{~mm}$ 
performed for OGIB than for other indications (Table 7) $[89,93]$. In one review of almost 3000 patients, the highest diagnostic yields with DBE were seen in OGIB (85.9\%), diarrhea (73.5\%), intestinal obstruction (62.9\%), weight loss (49.1\%), and abdominal pain (48.2\%) [94]. The mean procedural time ranged from 64.5 to 153.7 min, with an average time of $109.1 \mathrm{~min}$.

The risks of DBE are low, although higher compared to its counterpart in conventional endoscopy [95-97]. For instance, in one review of nine US-based centers comprising 2478 total DBE procedures, the overall adverse event rate was $0.9 \%$ for major complications, including 11 perforations $(0.4 \%), 6$ episodes of pancreatitis $(0.2 \%)$, and 4 episodes of bleeding $(0.2 \%)$. The risk of perforation appears to be higher with an anterograde approach than with a retrograde one [95]. In a separate European trial, 62 centers demonstrated a similar risk profile with a major complication rate of $1.2 \%$, including both perforation and pancreatitis [97]. Minor adverse events include abdominal pain, reddening of the mucosa, and slight intramucosal hemorrhage [98]. The risk of complications increases with therapeutic procedures compared to diagnostic procedures $(4.3 \%$ vs. $0.8 \%)$. Contraindications to DBE include suspected intestinal perforation, as well as esophageal varices, elevated bleeding risk, and overall poor medical condition [99].

\section{Single-Balloon Enteroscopy}

Introduced in 2007, SBE (Olympus Corp. of Japan, Tokyo, Japan) is another method of small bowel investigation. Like DBE, SBE uses a push-and-pull method to inch-worm the enteroscope through the small bowel. However, as its name implies, SBE relies on just a single balloon, located at the distal tip of the overtube, to pleat the small bowel over the enteroscope. Once the device reaches its extent, the balloon is inflated to anchor the overtube in position, and the enteroscope is advanced. The balloon is then deflated, the overtube advanced, and the steps repeated until the full length of the enteroscope has been inserted. SBE is available in both a diagnostic (SIF-Q180) and therapeutic (SIF-H290S) model and can also be used via an oral or rectal approach $[88,90]$.
SBE is a newer technique than DBE, and further studies are needed for a full comparison. However, given the published data to date, the two procedures appear similar in terms of diagnostic yield and complications. The overall diagnostic yield of SBE ranges from 47 to $60 \%$ [90, 98, 100]. The complication profile also mirrors that of DBE, with an overall adverse event rate of $1 \%$, which includes perforation and pancreatitis [101]. In one large multicenter comparison between SBE and DBE, there was no significant difference in diagnostic yield ( $43 \%$ vs. $37 \% ; p=0.59$ ) [101]. Likewise, a 2015 meta-analysis found no significant differences in diagnostic yield or therapeutic yield between the two procedures [102].

One theoretical disadvantage of SBE is that it cannot reach as far into the small bowel as DBE. SBE can reach just up to $133-256 \mathrm{~cm}$ from the ligament of Treitz with an anterograde approach and up to $73-163 \mathrm{~cm}$ from the ileocecal valve with a retrograde approach [90]. Nevertheless, this limitation has not been demonstrated to translate into poorer outcomes [103]. On the other hand, one major advantage of SBE is the shorter setup time. Multiple studies have now shown that setup times are shorter for SBE than DBE by 4-8 min, although overall procedural times appear to be similar [104, 105].

\section{Spiral Enteroscopy}

Compared to DBE and SBE, SE represents a novel approach to small bowel investigation. The Endo-Ease Discovery SB (Spirus Medical LLC, Stoughton, MA, USA) is the newest SE system, comprised of a spiral-shaped overtube that can be placed over the SIF-190 enteroscope. Rather than the push-and-pull method used in balloon enteroscopy, SE uses rotational mechanics to pleat the small bowel over the enteroscope. The Spirus device contains a soft plastic raised helix at the distal end of the overtube, which through clockwise rotation helps to pleat the small bowel over the enteroscope until the most distant extent of the small intestine has been reached $[88,90]$.

The design approach of SE has resulted in technical advantages compared to SBE and DBE, with shorter overall
Table 7 Testing characteristics of various device-assisted enteroscopy devices

\begin{tabular}{lllll}
\hline & $\begin{array}{l}\text { Diagnostic } \\
\text { yield (\%) }\end{array}$ & $\begin{array}{l}\text { Therapeutic } \\
\text { yield (\%) }\end{array}$ & $\begin{array}{l}\text { Major complica- } \\
\text { tion rate* }(\%)\end{array}$ & $\begin{array}{l}\text { Minor compli- } \\
\text { cation rate** } \\
(\%)\end{array}$ \\
\hline Double-balloon enteroscopy & $31-81$ & $9-72$ & $0.72-1.2$ & $0-9.1$ \\
Single-balloon enteroscopy & $37-61$ & $5-48$ & $\sim 0.02$ & $0-5.6$ \\
Spiral enteroscopy & $33.4-90$ & $57-92$ & $0-0.08$ & $0.02-0.64$ \\
Motorized spiral enteroscopy & 73 & 73 & 1.5 & 20 \\
\hline
\end{tabular}

*Major complications include perforation, pancreatitis, and bleeding

**Minor complications include abdominal pain, nausea, vomiting, mild mucosal trauma, and self-limited symptoms 
procedural times. In one recent systematic review, the procedural time for SE was significantly shorter than that of DBE. The overall time to reach maximal insertion is more controversial. In one prospective comparison, there were shorter times to reach maximal insertion with SE compared to DBE (24 $\min$ vs. $45 \mathrm{~min} ; p=0.0005$ ) [106]. However, once corrected for differences in depth of insertion, no significant differences were seen. In another RCT comparing procedural times between SE and SBE, no significant differences were found [107].

Indications for $\mathrm{SE}$ are similar to those for $\mathrm{DBE}$ and SBE [105-108]. In one RCT, the depth of maximal insertion of SE was greater than that of SBE $(330 \pm 88.2 \mathrm{~cm}$ vs. $285.3 \pm 80.8$ ) but this was not statistically significant [107]. Likewise, a meta-analysis of balloon enteroscopy versus spiral enteroscopy did not find a significant difference in the depth of maximal insertion between the two groups, with a mean difference of $26.29 \mathrm{~cm}$ [108]. The overall diagnostic yield for SE is also similar to that of DBE and SBE, ranging from 33 to $90 \%$ [108]. In a large trial of 148 patients undergoing SE, 101 of whom had OGIB, the diagnostic yield was $65 \%$ [109]. In a separate trial comparing SE to DBE, the diagnostic yield and therapeutic yield were $75 \%$ and $66 \%$ with SE, and 70\% and 70\% with DBE [110]. A 2017 metaanalysis suggested no significant differences in the rates of diagnostic or therapeutic success between DBE, SBE, or SE [108].

One limitation to SE is in its approach. To date, most studies using SE have utilized an anterograde approach. While SE has been studied with a rectal approach, this retrograde route was associated with greater technical difficulties and a lower rate of completion [88, 109-113]. Nevertheless, $\mathrm{SE}$ is overall a safe procedure [109].

\section{PowerSpiral Enteroscopy}

A new and innovative technology, PowerSpiral Enteroscopy (PSE) (Olympus Medical Systems Corporation, Tokyo, JP) was developed and introduced in 2015 [114]. The system is conceptually similar to manual spiral enteroscopy models but with the addition of an electric motor and flexible drive built into the scope. The motor rotates a spiral overtube located toward the end of the shaft, where it is better positioned to pleat the intestine over the enteroscope's insertion tube. A foot pedal is used to activate clockwise and counterclockwise rotation. In comparison to manual spiral enteroscopy, here the technology measures the resistance that the spiral rotation is applying to the tissue, then provides feedback and adjusts to prevent damage [102].

Clinical trials with PSE are ongoing. The first singlecenter feasibility trial measured outcomes in 30 patients and suggested that PSE is a safe and effective technology with a deeper insertion depth and shorter procedure times than the current DAE technologies $[114,115]$. According to an available abstract for the first prospective clinical trial, PSE had an overall complete enteroscopy rate of $70 \%$. Overall diagnostic and therapeutic yield were $73 \%$ and $73 \%$, respectively. No major complications such as perforation or pancreatitis were observed, but the total rate of minor complications was $20 \%$, including mucosal tears, hematoma, esophageal erosion, and throat discomfort [116]. More data are needed, however, PSE has the potential to provide deeper access to the small bowel with shorter procedural times compared to current technology.

\section{Combining Video Capsule Endoscopy and Device-Assisted Enteroscopy}

It is generally agreed that VCE and DAE are complementary technologies in most applications. Our strategy is to use VCE as the first line of investigation together with conventional upper and lower endoscopy as needed. This allows us to locate the lesion or source of bleeding, make an assessment as to whether the lesion is best managed by DAE or surgical intervention, and decide from which direction it might be best approached by DAE. This ideal situation is often modified by local resources and expertise. Furthermore, lesions in the middle third of the small intestine may not be reachable by DAE. This is a common occurrence for tumors and may lead to surgical intervention. In Europe and North America, SBB generally occurs more proximally, in contrast to Asian countries where SBB tends to originate more distally.

\section{Conclusion}

Over the last 20 years, VCE and DAE have been demonstrated to be complementary technologies for the diagnosis and management of small bowel pathology. Neither device is perfect, but the combination continues to evolve with everimproving technology. We can look forward to the use of AI that will improve our reading capabilities of VCE and to the evolution of the PowerSpiral. However, both will have their limitations and will continue to need refinements and provide new opportunities for the innovating gastroenterologist.

\section{Summary}

- VCE has a well-established role in a variety of diseases including small bowel bleeding (SBB), Crohn's disease (CD), and small intestinal neoplasia. 
- In acute gastrointestinal bleeding, accumulating evidence suggests that a VCE-first protocol can increase bleeding detection, reduce admission rates, and lower costs.

- VCE and DAE are complementary technologies. Using VCE as the first line of investigation allows us to locate a lesion or source of bleeding, thus enabling decisions to be made as to the approach for DAE or the need for surgery.

- The clinical indications, diagnostic yields, and complication rates between different device-assisted enteroscopy techniques are similar, and choice often depends on availability and local expertise.

- In resource-constrained settings, such as during the SARS-CoV-2 pandemic, a VCE-first protocol for acute GIB has been shown to reduce exposure to aerosolgenerating procedures and utilize fewer personnel and less personal protective equipment (PPE), thus making it an attractive initial test compared to conventional endoscopy.

\section{References}

1. Keuchel M, Hagenmuller F, Tajiri H. Video Capsule Endoscopy. Springer

2. Cave DR, Fleischer DE, Leighton JA et al. A multicenter randomized comparison of the Endocapsule and the Pillcam SB. Gastrointest Endosc. 2008;68:487-494. https://doi.org/10. 1016/j.gie.2007.12.037.

3. Hartmann D, Eickhoff A, Damian U, Riemann JF. Diagnosis of small-bowel pathology using paired capsule endoscopy with two different devices: a randomized study. Endoscopy. 2007;39:1041-1045. https://doi.org/10.1055/s-2007-966943.

4. Pioche M, Gaudin J-L, Filoche B et al. Prospective, randomized comparison of two small-bowel capsule endoscopy systems in patients with obscure GI bleeding. Gastrointest Endosc. 2011;73:1181-1188. https://doi.org/10.1016/j.gie. 2011.02.011.

5. Choi EH, Mergener K, Semrad C et al. A multicenter, prospective, randomized comparison of a novel signal transmission capsule endoscope to an existing capsule endoscope. Gastrointest Endosc. 2013;78:325-332. https://doi.org/10.1016/j.gie. 2013.02.039.

6. Dolak W, Kulnigg-Dabsch S, Evstatiev R, Gasche C, Trauner M, Püspök A. A randomized head-to-head study of smallbowel imaging comparing MiroCam and EndoCapsule. Endoscopy. 2012;44:1012-1020. https://doi.org/10.1055/s-00321310158

7. Pioche M, Vanbiervliet G, Jacob P et al. Prospective randomized comparison between axial- and lateral-viewing capsule endoscopy systems in patients with obscure digestive bleeding. Endoscopy. 2014;46:479-484. https://doi.org/10.1055/s-0033-13588 32.

8. Kim HM, Kim YJ, Kim HJ et al. A pilot study of sequential capsule endoscopy using mirocam and pillcam SB devices with different transmission technologies. Gut Liver. 2010;4:192-200. https://doi.org/10.5009/gnl.2010.4.2.192.
9. Rokkas T, Papaxoinis K, Triantafyllou K, Pistiolas D, Ladas SD. Does purgative preparation influence the diagnostic yield of small bowel video capsule endoscopy?: A meta-analysis. Am J Gastroenterol. 2009;104:219-227. https://doi.org/10.1038/ajg. 2008.63.

10. Belsey J, Crosta C, Epstein O et al. Meta-analysis: efficacy of small bowel preparation for small bowel video capsule endoscopy. Curr Med Res Opin. 2012;28:1883-1890. https://doi.org/ 10.1185/03007995.2012.747953.

11. Hookey L, Louw J, Wiepjes M et al. Lack of benefit of active preparation compared with a clear fluid-only diet in smallbowel visualization for video capsule endoscopy: results of a randomized, blinded, controlled trial. Gastrointest Endosc. 2017;85:187-193. https://doi.org/10.1016/j.gie.2016.07.028.

12. Magalhães-Costa $\mathrm{P}$, Carmo J, Bispo $\mathrm{M}$, Santos S, Chagas C. Superiority of the split-dose peg regimen for small-bowel capsule endoscopy: a randomized controlled trial. J Clin Gastroenterol. 2016;50:e65-70. https://doi.org/10.1097/MCG.0000000000 000460 .

13. Wu L, Cao Y, Liao C, Huang J, Gao F. Systematic review and meta-analysis of randomized controlled trials of Simethicone for gastrointestinal endoscopic visibility. Scand J Gastroenterol. 2011;46:227-235. https://doi.org/10.3109/00365521.2010. 525714.

14. Albert J, Göbel C-M, Lesske J, Lotterer E, Nietsch H, Fleig WE. Simethicone for small bowel preparation for capsule endoscopy: a systematic, single-blinded, controlled study. Gastrointest Endosc. 2004;59:487-491. https://doi.org/10.1016/s00165107(04)00003-3.

15. Ito $\mathrm{T}$, Ohata $\mathrm{K}$, Ono A et al. Prospective controlled study on the effects of polyethylene glycol in capsule endoscopy. World $J$ Gastroenterol. 2012;18:1789-1792. https://doi.org/10.3748/wjg. v18.i15.1789.

16. Lai LH, Wong GLH, Chow DKL, Lau JYW, Sung JJY, Leung WK. Long-term follow-up of patients with obscure gastrointestinal bleeding after negative capsule endoscopy. Am J Gastroenterol. 2006;101:1224-1228. https://doi.org/10.1111/j.1572-0241. 2006.00565.x.

17. Spada C, Riccioni ME, Costamagna G. Rapid access real-time device and rapid access software: new tools in the armamentarium of capsule endoscopy. Expert Rev Med Dev. 2007;4:431435. https://doi.org/10.1586/17434440.4.4.431.

18. Lucendo AJ, González-Castillo S, Fernández-Fuente M, De Rezende LC. Tracheal aspiration of a capsule endoscope: a new case report and literature compilation of an increasingly reported complication. Dig Dis Sci. 2011;56:2758-2762. https://doi.org/ 10.1007/s10620-011-1666-2.

19. Schneider ARJ, Hoepffner N, Rösch W, Caspary WF. Aspiration of an M2A capsule. Endoscopy. 2003;35:713. https://doi.org/10. 1055/s-2003-41527.

20. Buchkremer F, Herrmann T, Stremmel W. Mild respiratory distress after wireless capsule endoscopy. Gut. 2004;53:472.

21. Pezzoli A, Fusetti N, Carella A, Gullini S. Asymptomatic bronchial aspiration and prolonged retention of a capsule endoscope: a case report. J Med Case Reports. 2011;5:341. https://doi.org/ 10.1186/1752-1947-5-341.

22. Sinn I, Neef B, Andus T. Aspiration of a capsule endoscope. Gastrointest Endosc. 2004;59:926-927. https://doi.org/10.1016/ s0016-5107(04)00291-3.

23. Girdhar A, Usman F, Bajwa A. Aspiration of capsule endoscope and successful bronchoscopic extraction. J Bronchol Interv Pulmonol. 2012;19:328-331. https://doi.org/10.1097/LBR.0b013 e31826e3b53.

24 Ling C-R, Wang M-J, Zhuang W. Capsule retention for 7.5 years in Meckel's diverticulum. Dig Endosc Off J Jpn Gastroenterol 
Endosc Soc. 2017;29:386-387. https://doi.org/10.1111/den. 12795.

25. Araujo IK, Pages M, Romero C, Castells A, González-Suárez B. Twelve-year asymptomatic retention of a colon capsule endoscope. Gastrointest Endosc. 2017;85:681-682. https://doi.org/ 10.1016/j.gie.2016.04.045.

26. Bhattarai M, Bansal P, Khan Y. Longest duration of retention of video capsule: a case report and literature review. World $J$ Gastrointest Endosc. 2013;5:352-355. https://doi.org/10.4253/ wjge.v5.i7.352.

27 Gerson LB, Fidler JL, Cave DR, Leighton JA. ACG Clinical Guideline: Diagnosis and Management of Small Bowel Bleeding. Am J Gastroenterol. 2015;110:1265-1287. https://doi.org/ 10.1038/ajg.2015.246 (quiz 1288).

28. Katsinelos P, Lazaraki G, Gkagkalis A et al. The role of capsule endoscopy in the evaluation and treatment of obscure-overt gastrointestinal bleeding during daily clinical practice: a prospective multicenter study. Scand J Gastroenterol. 2014;49:862-870. https://doi.org/10.3109/00365521.2014.889209.

29. Bresci G, Parisi G, Bertoni M, Tumino E, Capria A. The role of video capsule endoscopy for evaluating obscure gastrointestinal bleeding: usefulness of early use. J Gastroenterol. 2005;40:256259. https://doi.org/10.1007/s00535-004-1532-5.

30. Lepileur L, Dray X, Antonietti M et al. Factors associated with diagnosis of obscure gastrointestinal bleeding by video capsule enteroscopy. Clin Gastroenterol Hepatol Off Clin Pract J Am Gastroenterol Assoc. 2012;10:1376-1380. https://doi.org/10. 1016/j.cgh.2012.05.024.

31. Carey EJ, Leighton JA, Heigh RI et al. A single-center experience of 260 consecutive patients undergoing capsule endoscopy for obscure gastrointestinal bleeding. Am J Gastroenterol. 2007;102:89-95. https://doi.org/10.1111/j.1572-0241.2006. 00941.x.

32. Marya NB, Wang L, Dasharathy S et al. Development of a scoring system to predict a positive diagnosis on video capsule endoscopy for suspected small bowel bleeding. TIGE. 2020;22:178-184.

33. Pennazio M, Santucci R, Rondonotti E et al. Outcome of patients with obscure gastrointestinal bleeding after capsule endoscopy: report of 100 consecutive cases. Gastroenterology. 2004;126:643-653. https://doi.org/10.1053/j.gastro.2003.11.057.

34. Delvaux M, Fassler I, Gay G. Clinical usefulness of the endoscopic video capsule as the initial intestinal investigation in patients with obscure digestive bleeding: validation of a diagnostic strategy based on the patient outcome after 12 months. Endoscopy. 2004;36:1067-1073. https://doi.org/10. 1055/s-2004-826034.

35. Rondonotti E, Villa F, Mulder CJJ, Jacobs MAJM, de Franchis R. Small bowel capsule endoscopy in 2007: indications, risks and limitations. World J Gastroenterol. 2007;13:6140-6149. https:// doi.org/10.3748/wjg.v13.i46.6140.

36. Kim J-B, Ye BD, Song Y et al. Frequency of rebleeding events in obscure gastrointestinal bleeding with negative capsule endoscopy. J Gastroenterol Hepatol. 2013;28:834-840. https://doi.org/ 10.1111/jgh.12145.

37. Koh S-J, Im JP, Kim JW et al. Long-term outcome in patients with obscure gastrointestinal bleeding after negative capsule endoscopy. World J Gastroenterol. 2013;19:1632-1638. https:// doi.org/10.3748/wjg.v19.i10.1632.

38. Jones BH, Fleischer DE, Sharma VK et al. Yield of repeat wireless video capsule endoscopy in patients with obscure gastrointestinal bleeding. Am J Gastroenterol. 2005;100:1058-1064. https://doi.org/10.1111/j.1572-0241.2005.40722.x.

39. Viazis N, Papaxoinis K, Vlachogiannakos J, Efthymiou A, Theodoropoulos I, Karamanolis DG. Is there a role for second-look capsule endoscopy in patients with obscure GI bleeding after a nondiagnostic first test? Gastrointest Endosc. 2009;69:850-856. https://doi.org/10.1016/j.gie.2008.05.053.

40. Saperas E, Dot J, Videla S et al. Capsule endoscopy versus computed tomographic or standard angiography for the diagnosis of obscure gastrointestinal bleeding. Am J Gastroenterol. 2007;102:731-737. https://doi.org/10.1111/j.1572-0241.2007. 01058.x.

41. Triester SL, Leighton JA, Leontiadis GI et al. A meta-analysis of the yield of capsule endoscopy compared to other diagnostic modalities in patients with obscure gastrointestinal bleeding. Am J Gastroenterol. 2005;100:2407-2418. https://doi.org/10.1111/j. 1572-0241.2005.00274.x.

42. Pennazio M, Spada C, Eliakim R et al. Small-bowel capsule endoscopy and device-assisted enteroscopy for diagnosis and treatment of small-bowel disorders: European Society of Gastrointestinal Endoscopy (ESGE) Clinical Guideline. Endoscopy. 2015;47:352-376. https://doi.org/10.1055/s-0034-1391855.

43. Goenka MK, Majumder S, Kumar S, Sethy PK, Goenka U. Single center experience of capsule endoscopy in patients with obscure gastrointestinal bleeding. World J Gastroenterol. 2011;17:774778. https://doi.org/10.3748/wjg.v17.i6.774.

44. Yamada A, Watabe H, Kobayashi Y, Yamaji Y, Yoshida H, Koike $\mathrm{K}$. Timing of capsule endoscopy influences the diagnosis and outcome in obscure-overt gastrointestinal bleeding. Hepatogastroenterology. 2012;59:676-679. https://doi.org/10.5754/hge12 180.

45. Singh A, Marshall C, Chaudhuri B et al. Timing of video capsule endoscopy relative to overt obscure GI bleeding: implications from a retrospective study. Gastrointest Endosc. 2013;77:761766. https://doi.org/10.1016/j.gie.2012.11.041.

46. Lichtenstein GR, Loftus EV, Isaacs KL, Regueiro MD, Gerson LB, Sands BE. ACG clinical guideline: management of crohn's disease in adults. Am J Gastroenterol. 2018;113:481-517. https:// doi.org/10.1038/ajg.2018.27.

47 Dionisio PM, Gurudu SR, Leighton JA et al. Capsule endoscopy has a significantly higher diagnostic yield in patients with suspected and established small-bowel Crohn's disease: a metaanalysis. Am J Gastroenterol. 2010;105:1240-1248. https://doi. org/10.1038/ajg.2009.713 (quiz 1249).

48. Jensen MD, Nathan T, Rafaelsen SR, Kjeldsen J. Diagnostic accuracy of capsule endoscopy for small bowel Crohn's disease is superior to that of MR enterography or CT enterography. Clin Gastroenterol Hepatol Off Clin Pract J Am Gastroenterol Assoc. 2011;9:124-129. https://doi.org/10.1016/j.cgh.2010.10.019.

49. Hall B, Holleran G, Costigan D, McNamara D. Capsule endoscopy: High negative predictive value in the long term despite a low diagnostic yield in patients with suspected Crohn's disease. United Eur Gastroenterol J. 2013;1:461-466. https://doi.org/10. $1177 / 2050640613508551$.

50. Lorenzo-Zúñiga V, de Vega VM, Domènech E, Cabré E, Mañosa M, Boix J. Impact of capsule endoscopy findings in the management of Crohn's Disease. Dig Dis Sci. 2010;55:411-414. https:// doi.org/10.1007/s10620-009-0758-8.

51. Redondo-Cerezo E. Role of wireless capsule endoscopy in inflammatory bowel disease. World J Gastrointest Endosc. 2010;2:179-185. https://doi.org/10.4253/wjge.v2.i5.179.

52. Mehdizadeh S, Chen GC, Barkodar L et al. Capsule endoscopy in patients with Crohn's disease: diagnostic yield and safety. Gastrointest Endosc. 2010;71:121-127. https://doi.org/10.1016/j.gie. 2009.06.034.

53. Long MD, Barnes E, Isaacs K, Morgan D, Herfarth HH. Impact of capsule endoscopy on management of inflammatory bowel disease: a single tertiary care center experience. Inflamm Bowel Dis. 2011;17:1855-1862. https://doi.org/10.1002/ibd.21571.

54. Pons Beltrán V, Nos P, Bastida G et al. Evaluation of postsurgical recurrence in Crohn's disease: A new indication for capsule 
endoscopy? Gastrointest Endosc. 2007;66:533-540. https://doi. org/10.1016/j.gie.2006.12.059.

55. Efthymiou A, Viazis N, Mantzaris G et al. Does clinical response correlate with mucosal healing in patients with Crohn's disease of the small bowel? A prospective, case-series study using wireless capsule endoscopy. Inflamm Bowel Dis. 2008;14:1542-1547. https://doi.org/10.1002/ibd.20509.

56. Gralnek IM, Ching JYL, Maza I et al. Capsule endoscopy in acute upper gastrointestinal hemorrhage: a prospective cohort study. Endoscopy. 2013;45:12-19. https://doi.org/10.1055/s0032-1325933.

57. Gal E, Geller A, Fraser G, Levi Z, Niv Y. Assessment and validation of the new capsule endoscopy Crohn's disease activity index (CECDAI). Dig Dis Sci. 2008;53:1933-1937. https://doi.org/10. 1007/s10620-007-0084-y.

58. Niv Y, Ilani S, Levi Z et al. Validation of the Capsule Endoscopy Crohn's Disease Activity Index (CECDAI or Niv score): a multicenter prospective study. Endoscopy. 2012;44:21-26. https://doi. org/10.1055/s-0031-1291385.

59. Marya NB, Jawaid S, Foley A et al. A randomized controlled trial comparing efficacy of early video capsule endoscopy with standard of care in the approach to nonhematemesis GI bleeding (with videos). Gastrointest Endosc. 2019;89:33-43.e4. https:// doi.org/10.1016/j.gie.2018.06.016.

60. Sung JJY, Tang RSY, Ching JYL, Rainer TH, Lau JYW. Use of capsule endoscopy in the emergency department as a triage of patients with GI bleeding. Gastrointest Endosc. 2016;84:907913. https://doi.org/10.1016/j.gie.2016.04.043.

61. Gutkin E, Shalomov A, Hussain SA et al. Pillcam ESO(®) is more accurate than clinical scoring systems in risk stratifying emergency room patients with acute upper gastrointestinal bleeding. Ther Adv Gastroenterol. 2013;6:193-198. https://doi.org/10. 1177/1756283X13481020.

62. Meltzer AC, Ward MJ, Gralnek IM, Pines JM. The cost-effectiveness analysis of video capsule endoscopy compared to other strategies to manage acute upper gastrointestinal hemorrhage in the ED. Am J Emerg Med. 2014;32:823-832. https://doi.org/10. 1016/j.ajem.2013.11.012.

63. Hakimian S, Hanscom M, Petersile M, et al. Video Capsule Endoscopy as First Procedure for Acute Gastrointestinal Bleeding: An Approach to Minimizing Exposure to SARS-CoV-2 and Preserving Resources [abstract]. In: ACG 2020 Virtual Annual Scientific Meeting; 2020 Oct 23-28.

64. Eliakim R, Fireman Z, Gralnek IM et al. Evaluation of the PillCam Colon capsule in the detection of colonic pathology: results of the first multicenter, prospective, comparative study. Endoscopy. 2006;38:963-970. https://doi.org/10.1055/s-2006-944832.

65. Eliakim R, Sharma VK, Yassin K et al. A prospective study of the diagnostic accuracy of PillCam ESO esophageal capsule endoscopy versus conventional upper endoscopy in patients with chronic gastroesophageal reflux diseases. J Clin Gastroenterol. 2005;39:572-578. https://doi.org/10.1097/01.mcg.0000170764. 29202.24

66. Bhardwaj A, Hollenbeak CS, Pooran N, Mathew A. A meta-analysis of the diagnostic accuracy of esophageal capsule endoscopy for Barrett's esophagus in patients with gastroesophageal reflux disease. Am J Gastroenterol. 2009;104:1533-1539. https://doi. org/10.1038/ajg.2009.86.

67. de Franchis R, Eisen GM, Laine L et al. Esophageal capsule endoscopy for screening and surveillance of esophageal varices in patients with portal hypertension. Hepatol Baltim Md. 2008;47:1595-1603. https://doi.org/10.1002/hep.22227.

68. Spada C, Hassan C, Galmiche JP et al. Colon capsule endoscopy: European Society of Gastrointestinal Endoscopy (ESGE) Guideline. Endoscopy. 2012;44:527-536. https://doi.org/10. 1055/s-0031-1291717.
69. Spada C, Hassan C, Munoz-Navas M et al. Second-generation colon capsule endoscopy compared with colonoscopy. Gastrointest Endosc. 2011;74:581-589.e1. https://doi.org/10.1016/j.gie. 2011.03.1125.

70. Pioche M, de Leusse A, Filoche B et al. Prospective multicenter evaluation of colon capsule examination indicated by colonoscopy failure or anesthesia contraindication. Endoscopy. 2012;44:911-916. https://doi.org/10.1055/s-0032-1310008.

71. Alarcón-Fernández $\mathrm{O}$, Ramos L, Adrián-de-Ganzo Z et al. Effects of colon capsule endoscopy on medical decision making in patients with incomplete colonoscopies. Clin Gastroenterol Hepatol Off Clin Pract J Am Gastroenterol Assoc. 2013;11:534540.e1. https://doi.org/10.1016/j.cgh.2012.10.016.

72. Triantafyllou K, Viazis N, Tsibouris P et al. Colon capsule endoscopy is feasible to perform after incomplete colonoscopy and guides further workup in clinical practice. Gastrointest Endosc. 2014;79:307-316. https://doi.org/10.1016/j.gie.2013.07.061.

73. Spada C, Hassan C, Barbaro B et al. Colon capsule versus CT colonography in patients with incomplete colonoscopy: a prospective, comparative trial. Gut. 2015;64:272-281. https://doi org/10.1136/gutjnl-2013-306550.

74. Keller J, Fibbe C, Volke F et al. Remote magnetic control of a wireless capsule endoscope in the esophagus is safe and feasible: results of a randomized, clinical trial in healthy volunteers. Gastrointest Endosc. 2010;72:941-946. https://doi.org/10.1016/j. gie.2010.06.053

75. Keller J, Fibbe C, Volke F et al. Inspection of the human stomach using remote-controlled capsule endoscopy: a feasibility study in healthy volunteers (with videos). Gastrointest Endosc. 2011;73:22-28. https://doi.org/10.1016/j.gie.2010.08.053.

76. Rahman I, Pioche M, Shim CS et al. Magnetic-assisted capsule endoscopy in the upper GI tract by using a novel navigation system (with video). Gastrointest Endosc. 2016;83:889-895.e1. https://doi.org/10.1016/j.gie.2015.09.015.

77. Liao Z, Hou X, Lin-Hu E-Q et al. Accuracy of magnetically controlled capsule endoscopy, compared with conventional gastroscopy, in detection of gastric diseases. Clin Gastroenterol Hepatol Off Clin Pract J Am Gastroenterol Assoc. 2016;14:1266-1273. e1. https://doi.org/10.1016/j.cgh.2016.05.013.

78. Sharma VK. The future is wireless: advances in wireless diagnostic and therapeutic technologies in gastroenterology. Gastroenterology. 2009;137:434-439. https://doi.org/10.1053/j. gastro.2009.06.029.

79. Singeap A-M, Stanciu C, Trifan A. Capsule endoscopy: the road ahead. World J Gastroenterol. 2016;22:369-378. https:// doi.org/10.3748/wjg.v22.i1.369.

80. Ray K. Endoscopy: Tethered capsule endomicroscopy of the oesophagus-an easy pill to swallow. Nat Rev Gastroenterol Hepatol. 2013;10:129. https://doi.org/10.1038/nrgastro.2013. 15.

81. Wang L, Zhang G, Luo JC et al. Wireless spectroscopic compact photonic explorer for diagnostic optical imaging. Biomed Microdevices. 2005;7:111-115. https://doi.org/10.1007/ s10544-005-1588-x.

82. Zhang H, Morgan D, Cecil G et al. Biochromoendoscopy: molecular imaging with capsule endoscopy for detection of adenomas of the GI tract. Gastrointest Endosc. 2008;68:520-527. https:// doi.org/10.1016/j.gie.2008.02.023.

83. Saito H, Aoki T, Aoyama K et al. Automatic detection and classification of protruding lesions in wireless capsule endoscopy images based on a deep convolutional neural network. Gastrointest Endosc. 2020;92:144-151.e1. https://doi.org/10.1016/j.gie. 2020.01.054.

84. Aoki T, Yamada A, Kato Y et al. Automatic detection of blood content in capsule endoscopy images based on a deep 
convolutional neural network. J Gastroenterol Hepatol. 2020;35:1196-1200. https://doi.org/10.1111/jgh.14941.

85. Aoki T, Yamada A, Aoyama K et al. Automatic detection of erosions and ulcerations in wireless capsule endoscopy images based on a deep convolutional neural network. Gastrointest Endosc. 2019;89:357-363.e2. https://doi.org/10.1016/j.gie.2018.10.027.

86. Ding Z, Shi H, Zhang $\mathrm{H}$ et al. Gastroenterologist-level identification of small-bowel diseases and normal variants by capsule endoscopy using a deep-learning model. Gastroenterology. 2019;157:1044-1054.e5. https://doi.org/10.1053/j.gastro.2019. 06.025 .

87. Yamamoto H, Sekine Y, Sato Y et al. Total enteroscopy with a nonsurgical steerable double-balloon method. Gastrointest Endosc. 2001;53:216-220. https://doi.org/10.1067/mge.2001. 112181.

88. Schneider M, Höllerich J, Beyna T. Device-assisted enteroscopy: a review of available techniques and upcoming new technologies. World J Gastroenterol. 2019;25:3538-3545. https://doi.org/10. 3748/wjg.v25.i27.3538.

89 Raju GS, Gerson L, Das A, Lewis B. American Gastroenterological Association: American Gastroenterological Association (AGA) Institute technical review on obscure gastrointestinal bleeding. Gastroenterology. 2007;133:1697-1717. https://doi. org/10.1053/j.gastro.2007.06.007.

90. Khashab MA, Pasha SF, Muthusamy VR et al. The role of deep enteroscopy in the management of small-bowel disorders. Gastrointest Endosc. 2015;82:600-607. https://doi.org/10.1016/j.gie. 2015.06.046.

91. ASGE Standards of Practice Committee, Early DS, Ben-Menachem T, et al. Appropriate use of GI endoscopy. Gastrointest Endosc. 2012;75(6):1127-1131. https://doi.org/10.1016/j.gie. 2012.01.011

92. Kawamura T, Uno K, Tanaka K, Yasuda K. Current status of single-balloon enteroscopy: insertability and clinical applications. World J Gastrointest Endosc. 2015;7:59-65. https://doi. org/10.4253/wjge.v7.i1.59.

93. Xin L, Liao Z, Jiang Y-P, Li Z-S. Indications, detectability, positive findings, total enteroscopy, and complications of diagnostic double-balloon endoscopy: a systematic review of data over the first decade of use. Gastrointest Endosc. 2011;74:563-570. https://doi.org/10.1016/j.gie.2011.03.1239.

94. Tang L, Huang L-Y, Cui J, Wu C-R. Effect of double-balloon enteroscopy on diagnosis and treatment of small-bowel diseases. Chin Med J (Engl). 2018;131:1321-1326. https://doi.org/10. 4103/0366-6999.232802.

95. Gerson LB, Tokar J, Chiorean M et al. Complications associated with double balloon enteroscopy at nine US centers. Clin Gastroenterol Hepatol Off Clin Pract J Am Gastroenterol Assoc. 2009;7:1177-1182. https://doi.org/10.1016/j.cgh.2009.07.005.

96. Mensink PBF, Haringsma J, Kucharzik T et al. Complications of double balloon enteroscopy: a multicenter survey. Endoscopy. 2007;39:613-615. https://doi.org/10.1055/s-2007-966444.

97 Möschler O, May A, Müller MK, Ell C. German DBE Study Group: Complications in and performance of double-balloon enteroscopy (DBE): results from a large prospective DBE database in Germany. Endoscopy. 2011;43:484-489. https://doi.org/10. 1055/s-0030-1256249.

98. Ramchandani M, Reddy DN, Gupta R et al. Diagnostic yield and therapeutic impact of single-balloon enteroscopy: Series of 106 cases. J Gastroenterol Hepatol. 2009;24:1631-1638. https://doi. org/10.1111/j.1440-1746.2009.05936.x.

99. Tanaka S, Mitsui K, Tatsuguchi A et al. Current status of double balloon endoscopy-indications, insertion route, sedation, complications, technical matters. Gastrointest Endosc. 2007;66:S30-33. https://doi.org/10.1016/j.gie.2007.01.026.
100. Upchurch BR, Sanaka MR, Lopez AR, Vargo JJ. The clinical utility of single-balloon enteroscopy: a single-center experience of 172 procedures. Gastrointest Endosc. 2010;71:1218-1223. https://doi.org/10.1016/j.gie.2010.01.012.

101. Domagk D, Mensink P, Aktas H et al. Single- versus doubleballoon enteroscopy in small-bowel diagnostics: a randomized multicenter trial. Endoscopy. 2011;43:472-476. https://doi.org/ 10.1055/s-0030-1256247.

102. Wadhwa V, Sethi S, Tewani $S$ et al. A meta-analysis on efficacy and safety: single-balloon versus double-balloon enteroscopy. Gastroenterol Rep. 2015;3:148-155. https://doi.org/10.1093/gastro/gov003.

103. Kim TJ, Kim ER, Chang DK, Kim Y-H, Hong SN. Comparison of the efficacy and safety of single- versus double-balloon enteroscopy performed by endoscopist experts in single-balloon enteroscopy: a single-center experience and meta-analysis. Gut Liver. 2017;11:520-527. https://doi.org/10.5009/gnl16330.

104. May A, Färber M, Aschmoneit I et al. Prospective multicenter trial comparing push-and-pull enteroscopy with the single- and double-balloon techniques in patients with small-bowel disorders. Am J Gastroenterol. 2010;105:575-581. https://doi.org/10. 1038/ajg.2009.712.

105. Efthymiou M, Desmond PV, Brown G et al. SINGLE-01: a randomized, controlled trial comparing the efficacy and depth of insertion of single- and double-balloon enteroscopy by using a novel method to determine insertion depth. Gastrointest Endosc. 2012;76:972-980. https://doi.org/10.1016/j.gie.2012.06.033.

106. Despott EJ, Murino A, Bourikas L, Nakamura M, Ramachandra $\mathrm{V}$, Fraser C. A prospective comparison of performance during back-to-back, anterograde manual spiral enteroscopy and doubleballoon enteroscopy. Dig Liver Dis Off J Ital Soc Gastroenterol Ital Assoc Study Liver. 2015;47:395-400. https://doi.org/10. 1016/j.dld.2015.02.003.

107. Moran RA, Barola S, Law JK et al. A randomized controlled trial comparing the depth of maximal insertion between anterograde single-balloon versus spiral enteroscopy. Clin Med Insights Gastroenterol. 2018;11:1179552218754881. https://doi.org/10.1177/ 1179552218754881.

108. Baniya R, Upadhaya S, Subedi SC et al. Balloon enteroscopy versus spiral enteroscopy for small-bowel disorders: a systematic review and meta-analysis. Gastrointest Endosc. 2017;86:9971005. https://doi.org/10.1016/j.gie.2017.06.015.

109 Morgan D, Upchurch B, Draganov P et al. Spiral enteroscopy: prospective US multicenter study in patients with small-bowel disorders. Gastrointest Endosc. 2010;72:992-998. https://doi. org/10.1016/j.gie.2010.07.013.

110. Rahmi G, Samaha E, Vahedi K et al. Multicenter comparison of double-balloon enteroscopy and spiral enteroscopy. J Gastroenterol Hepatol. 2013;28:992-998. https://doi.org/10.1111/jgh.12188.

111. May A, Manner H, Aschmoneit I, Ell C. Prospective, cross-over, single-center trial comparing oral double-balloon enteroscopy and oral spiral enteroscopy in patients with suspected smallbowel vascular malformations. Endoscopy. 2011;43:477-483. https://doi.org/10.1055/s-0030-1256340.

112. Messer I, May A, Manner H, Ell C. Prospective, randomized, single-center trial comparing double-balloon enteroscopy and spiral enteroscopy in patients with suspected small-bowel disorders. Gastrointest Endosc. 2013;77:241-249. https://doi.org/10. 1016/j.gie.2012.08.020.

113. Khashab MA, Lennon AM, Dunbar KB et al. A comparative evaluation of single-balloon enteroscopy and spiral enteroscopy for patients with mid-gut disorders. Gastrointest Endosc. 2010;72:766-772. https://doi.org/10.1016/j.gie.2010.04.043. 
114. Neuhaus H, Beyna T, Schneider M, Devière J. Novel motorized spiral enteroscopy: first clinical case. VideoGIE. 2016;1:32-33. https://doi.org/10.1016/j.vgie.2016.08.005.

115. Beyna T, Schneider M, Pullmann D, Gerges C, Kandler J, Neuhaus H. Motorized spiral colonoscopy: a first single-center feasibility trial. Endoscopy. 2018;50:518-523. https://doi.org/10. 1055/s-0043-123577.
116. Beyna T, Arvanitakis M, Schneider M, Hoellerich J, Deviere J, Neuhaus H. 47 First prospective clinical trial on total motorized spiral enteroscopy (TMSET). Gastrointest Endosc. 2019;89.

Publisher's Note Springer Nature remains neutral with regard to jurisdictional claims in published maps and institutional affiliations.

\section{Authors and Affiliations}

\section{Mark Hanscom $^{1} \cdot$ Courtney Stead ${ }^{2} \cdot$ Harris Feldman $^{2} \cdot$ Neil B. Marya $^{1} \cdot$ David Cave $^{1}$}

$\triangle$ Neil B. Marya

neil.marya@umassmed.edu

1 Division of Gastroenterology, University of Massachusetts Medical School, Worcester, MA 01655, USA
2 Department of Medicine, University of Massachusetts Medical School, Worcester, MA, USA 